\title{
CARACTERIZAÇÃO MOLECULAR DE POPULAÇÕES DE Butia capitata (Arecaceae) DO SUL DO BRASIL ATRAVÉS DE MARCADORES AFLP ${ }^{1}$
}

\author{
MIRIAM VALLI BUTTOW², CAROLINE MARQUES CASTRO ${ }^{3}$, ELISANE SCHWARTZ $^{4}$, \\ ADILSON TONIETTO ${ }^{5}$, ROSA LÍA BARBIERI $^{6}$
}

RESUMO - O gênero Butia (Arecaceae) é um pequeno gênero subtropical com espécies no sul da América do Sul, considerado ornamental. Além disso, seus frutos são apreciados pelo sabor e aroma peculiares. Porém, no Rio Grande do Sul, as populações naturais sofrem com o avanço das atividades rurais e da construção imobiliária. O objetivo deste trabalho foi caracterizar oito populações de Butia capitata ocorrentes no Rio Grande do Sul, através de marcadores moleculares do tipo AFLP. Pela análise molecular da variância, foi possível verificar que $83,68 \%$ da variabilidade genética são atribuídos à variação entre populações e $13,67 \%$ são atribuídos a diferenças entre populações dentro de regiões. A análise comparativa entre as oito populações feita de duas a duas demonstrou que são significativas as diferenças entre 15 populações, com média de $14,72 \%$ da variação molecular atribuída às diferenças entre populações. Este resultado indica a presença de variabilidade genética distribuída entre todas as populações, sem subdivisão decorrente de isolamento geográfico.

Termos para indexação: palmeiras, divergência genética, recursos genéticos, marcadores moleculares.

\section{MOLECULAR CHARACTERIZATION OF BUTIA CAPITATA POPULATIONS (ARECACEAE) IN THE SOUTHERN BRAZIL ESTIMATED BY AFLP ANALYSIS}

\begin{abstract}
The Butia genus (Arecaceae) is a small genus with subtropical species distributed in South America widely used as an ornamental plant. Besides, its fruits are appreciated for its unique flavor and aroma. But in some regions of the state of Rio Grande do Sul natural populations suffer with the progress of rural activities and development of buildings. The aim of this study, therefore, was characterizing eight populations of Butia capitata through AFLP markers. By analysis of molecular variance was possible to verify that $83.68 \%$ of the genetic variability is attributed to variation among populations and $13.67 \%$ is attributed to differences among populations within regions. In the pair-wise analysis, differences between 15 populations were significant, with an average of $14.72 \%$ of molecular variation attributed to differences between populations. This result indicates the presence of genetic variability distributed among all populations, without subdivision arising from geographical isolation.
\end{abstract}

Index terms: palms, genetic divergence, genetic resources, molecular markers.

\section{INTRODUÇÃO}

As espécies de Butia, pertencentes à família Arecaceae, compõem um pequeno gênero subtropical, com distribuição ao sul da América do Sul (Marcato, 2004). Seus frutos são intensamente utilizados para consumo processado e in natura, e a planta é considerada ornamental. Entretanto, as populações do Estado do Rio Grande do Sul estão sob contínua pressão devido à expansão agrícola e à especulação imobiliária que causam a degradação do seu habitat (Rivas \& Barilani, 2004; Rossato et al., 2007).
Alguns estudos recentes têm contribuído para elucidar importantes aspectos relacionados à biologia deste gênero. Análises citogenéticas demonstram que as espécies do gênero Butia ocorrentes no Rio Grande do Sul são diploides $(2 \mathrm{n}=32)$ (Gaiero \& Mazzella, 2005; Corrêa et al.2009). Recentemente, foram elaborados estudos de caracterização molecular com marcadores ISSR (Rossato et al., 2007) e RAPD (Nunes, 2007), que detectaram variabilidade nas populações estudadas. Castellani et al. (1998) estudaram aspectos da biologia reprodutiva de Butia capitata em uma região de Santa Catarina, contudo, 
ainda não há informação sobre a existência de barreiras reprodutivas que impeçam a autofecundação. De fato, ainda são poucas as informações científicas a respeito destas plantas que possam colaborar para sua utilização em programas de conservação e melhoramento.

Dentre os marcadores mais utilizados atualmente para estudos de genética populacional, o AFLP (amplified fragment length polymorphism) é uma técnica multilócus (Vos et al., 1995) com alto índice de eficiência devido à possibilidade de analisar um grande número de bandas simultaneamente com ampla cobertura do genoma. O perfil de bandas de AFLP é o resultado de variações nos sítios de restrição das enzimas utilizadas (Spooner et al., 2005). Uma de suas vantagens é que pode ser usada em organismos para os quais não existem informações genéticas prévias (Bonin et al., 2007; Vuylsteke et al., 2007), como é o caso de Butia.

Considerando o atual estado de destruição de grande parte dos palmares, são imprescindíveis trabalhos de caracterização morfológica e molecular que contribuam para o conhecimento da variabilidade e forneçam informações para a estruturação de programas de conservação e de melhoramento genético. Nesse contexto, o objetivo deste trabalho foi fazer a caracterização molecular de populações de Butia capitata do sul do Rio Grande do Sul, através do uso de marcadores AFLP.

\section{MATERIAL E MÉTODOS}

Este trabalho foi desenvolvido no Laboratório de Biologia Molecular da Embrapa Clima Temperado, Pelotas-RS, Brasil. Para a extração de material biológico, foram coletadas folhas de Butia capitata de três populações na região de Santa Vitória do Palmar, três populações na região de Rio Grande e duas populações na região de Tapes (Tabela 1). Foram coletadas as folhas mais jovens da planta, caracterizadas pela coloração amarela, por estarem dentro da bainha foliar e por serem menos rígidas que as folhas maduras. As populações foram georreferenciadas com o auxílio de um aparelho GPS Garmim Plus III e os locais de coletas estão representados na Figura 1.

As amostras foram trituradas com gelo seco, utilizando um processador de alimentos e armazenadas em ultrafreezer a $-80^{\circ} \mathrm{C}$. Foi procedida a extração de DNA dos 55 indivíduos coletados, conforme técnica descrita por Ferreira \& Grattapaglia (1995). A quantificação do DNA extraído foi feita em gel de agarose a $1 \%$, corado com solução a $0,02 \%$ de brometo de etídeo (10mg.mL $\left.\mathrm{mL}^{-1}\right)$ e visualizado em transiluminador de luz ultravioleta. A estimativa da

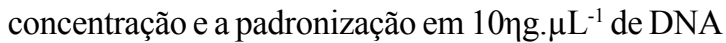
como solução de trabalho foram realizadas com base na comparação visual da intensidade das bandas com o padrão de peso molecular $\lambda$ DNA/Hind III.

A primeira etapa do AFLP, a digestão, foi realizada segundo protocolo descrito por Vos et al. (1995), com algumas modificações. Foram utilizados reagentes do kit $\mathrm{AFLP}^{\circledR}$ Analysis System I. O DNA genômico, na concentração de $100 \eta$ g (10ng. $\left.\mu \mathrm{L}^{-1}\right)$, foi digerido com $2 \mu \mathrm{L}$ de enzimas de restrição EcoRI/ MseI $\left(1,25 \mathrm{U} . \mu \mathrm{L}^{-1}\right)$ em tampão 5x [Tris- $\mathrm{HCl}(\mathrm{pH} 7.5)$ $10 \mathrm{mM}$, acetato $\mathrm{Mg} 10 \mathrm{mM}$, acetato $\mathrm{K} 50 \mathrm{mM}$ ] e $8 \mu \mathrm{L}$ de água MilliQ ${ }^{\circledR}$ para completar o volume final de reação $(25 \mu \mathrm{L})$. As amostras foram incubadas durante três horas a $37^{\circ} \mathrm{C}$, seguido por um período de $15 \mathrm{~min}$ a $70^{\circ} \mathrm{C}$. A ligação dos adaptadores foi feita logo após a digestão. Em um novo tubo, foram transferidos $10 \mu \mathrm{L}$ do DNA digerido anteriormente, sendo adicionados $9,6 \mu \mathrm{L}$ da solução de ligação de adaptadores e $0,4 \mu \mathrm{L}$ da enzima T4 DNA ligase, completando o volume final de $20 \mu \mathrm{L}$. Esta solução permaneceu incubando por duas horas a $20^{\circ} \mathrm{C}$. Após a ligação dos adaptadores foi feita uma diluição na proporção $1: 5$ em água MilliQ $^{\circledR}$, com um volume final de $25 \mu \mathrm{L}$.

A reação de pré-amplificação foi realizada conforme protocolo descrito por Vuylsteke et al. (2007) com algumas modificações. A partir de $1 \mu \mathrm{L}$ da solução de adaptadores diluída (1:5), foram adicionados à reação $0,3 \mu \mathrm{L}$ do primer EcoRI+1 (50ng. $\left.\mu \mathrm{L}^{-1}\right), 0,3 \mu \mathrm{L}$ do primer MseI+1 (50ng. $\mu \mathrm{L}^{-1}$ ), $0,2 \mu \mathrm{L}$ de Taq DNA polimerase ( $\left.5 \mathrm{U} \cdot \mu \mathrm{L}^{-1}\right), 1 \mu \mathrm{L}$ do 10X PCR Buffer [Tris-HCl pH 8,4 (20mM), KCl (50mM)], $0,5 \mu \mathrm{L}$ de $\mathrm{MgCl}_{2}(50 \mathrm{mM}), 0,8 \mu \mathrm{L}$ de dNTP mix $(2,5 \mathrm{mM})$ e $5,9 \mu \mathrm{L}$ água MilliQ ${ }^{\circledR}$ para completar o volume final de $10 \mu \mathrm{L}$. O programa de PCR utilizado foi o sugerido por Vuylsteke et al. (2007). Antes da amplificação seletiva, foi feita uma diluição de 1:5 em água MilliQ ${ }^{\circledR}$ autoclavada.

A amplificação seletiva final foi procedida a partir de $2,5 \mu \mathrm{L}$ da diluição da pré-amplificação. $\mathrm{O}$ mix da amplificação final foi composto de $1 \mu \mathrm{L}$ de 10x PCR buffer [200 mM Tris-HCl (pH 8.4), 500 $\mathrm{mM} \mathrm{KCl}], 0,4 \mu \mathrm{L}$ de $\mathrm{MgCl}_{2}(50 \mathrm{mM}), 8 \mu \mathrm{L}$ de dNTP mix $(2,5 \mathrm{mM}), 0,3 \mu \mathrm{L}$ de BSA $\left(10 \mathrm{mg}^{\mathrm{mL}} \mathrm{mL}^{-1}\right), 0,2 \mu \mathrm{L}$ de Taq DNA polimerase $\left(5 \mathrm{U} . \mu \mathrm{L}^{-1}\right), 2,0 \mu \mathrm{L}$ do primer EcoRI+3 (50ng. $\left.\mu \mathrm{L}^{-1}\right), 0,3 \mu \mathrm{L}$ do primer MseI+3 (50ng. $\mu \mathrm{L}^{-1}$ ) e $1,7 \mu \mathrm{L}$ de água MilliQ ${ }^{\circledR}$ autoclavada até completar o volume final de $10 \mu \mathrm{L}$. Nesta etapa, foi utilizado o programa de PCR de Vos et al. (1995). As combinações de primers utilizadas foram as seguintes: EcoRI/ MseI E-AGC/M-CTT, E-AGG/M-CAG, E-ACA/M-CAG e E- ACA/M-CAT. 
Após a amplificação final, foram adicionados $4 \mu \mathrm{L}$ da solução-tampão de carregamento (formamida deionizada $99 \%$, EDTA $10 \mathrm{mM}, 0,025 \%$ de xilenocianol e $0,025 \%$ de azul de bromofenol) e procedida a desnaturação das amostras a $94^{\circ} \mathrm{C}$, por $5 \mathrm{~min}$. Os fragmentos foram separados em gel de sequenciamento (poliacrilamida $6 \% \mathrm{p} / \mathrm{v}$, ureia $7 \mathrm{M}$ ) a partir de $6 \mu \mathrm{L}$ da solução, em uma corrida a $60 \mathrm{~W}$ durante três horas. Os fragmentos amplificados foram visualizados após coloração do gel com Nitrato de Prata $\left(\mathrm{AgNO}_{3}\right)$, seguindo protocolo descrito por Creste et al. (2001). O tamanho dos alelos foi estimado em comparação visual com o marcador de peso molecular de DNA de $25 \mathrm{pb}$.

Os produtos do AFLP foram designados como "1" para presença e " 0 " para ausência de bandas. Somente as bandas que apresentaram constância e nitidez nos géis foram analisadas, e com base nos dados obtidos da leitura dos géis foi construída uma matriz binária.

A partir da matriz original gerada com os dados de presença e ausência de marcadores em locos polimórficos, foi estimada a distância euclidiana entre os indivíduos. Com base no quadrado da distância euclidiana, foram calculadas as estimativas da variabilidade genética entre regiões, entre populações dentro de regiões e dentro de populações através da análise molecular da variância (AMOVA). O valor Fst, que representa a distância genética entre duas populações, foi utilizado para comparar a variação genética entre as oito populações avaliadas (Excoffier et al., 1992; Huff et al., 1993). Para testar a significância dos resultados da AMOVA, foi utilizado o método não paramétrico de permutações (Excoffier et al., 1992).

A similaridade entre os indivíduos foi estimada segundo o coeficiente de Jaccard (Bonin et al., 2007) através da fórmula $\mathrm{Sij}=\mathrm{a} /(\mathrm{a}+\mathrm{b}+\mathrm{c})$. Com base nos coeficientes de similaridade, foi construído um dendrograma, adotando como critério de agrupamento o método UPGMA (unweighted pair-group method of arithmetic averages) (Dias, 1998). Foi estimado o coeficiente de correlação cofenética entre a matriz de similaridade e o dendrograma obtido. Estas análises foram realizadas com o auxílio do programa NTSYSpc versão 2.01 (Rohlf, 2001).

\section{RESULTADOS E DISCUSSÃO}

Dos 55 indivíduos inicialmente amostrados, nove não apresentaram produtos amplificados nas análises realizadas, sendo descartados. Portanto, foram caracterizados 46 indivíduos (Tabela 1, Figura 2). As bandas polimórficas amplificadas pelas quatro combinações de primers variaram de 41 (E- AGC/ M- CTT) a 60 (E-AGG/ M-CAG), com uma média de 50 bandas polimórficas entre 500 e 72 pb (Tabela 2). Esta média de bandas polimórficas foi encontrada também por Bresolin-Soares (2007) em um estudo de diversidade genética, em populações de azevém. A combinação E-AGG/ M-CAG foi a que gerou o maior número de fragmentos polimórficos, e a combinação E-AGC/ M-CTT gerou o menor polimorfismo. As quatro combinações geraram um total de 214 fragmentos e, destes, 199 (93,5\%) foram polimórficos. Em um trabalho sobre diversidade genética feito com outra espécie de Arecaceae, Euterpe edulis Mart., Cardoso et al. (2000) obtiveram uma proporção de cerca de $92 \%$ de marcadores polimórficos ao analisar cinco combinações de primers. Segundo estes autores, outros trabalhos apresentam resultados similares em relação ao polimorfismo, como no caso da espécie arbórea Caesalpinea echinata Lam. Este polimorfismo mostrado pelas análises com o marcador AFLP é resultante de diversos tipos de mutações que levam à perda ou ganho de um local de restrição reconhecido pelas enzimas utilizadas na digestão, ou pela alteração da sequência reconhecida pelos nucleotídeos arbitrários nos terminais 3' dos iniciadores (Cavalli, 2003).

A partir dos dados de presença e ausência dos marcadores polimórficos, foi estimada a variabilidade genética entre regiões, entre populações dentro de regiões e dentro de populações pela análise molecular da variância, AMOVA (Tabela 3). A variação genética entre as regiões não foi significativa, indicando que não ocorre subdivisão de populações em função da região geográfica. Por outro lado, as diferenças entre populações dentro de região e dentro de populações foram significativas (Tabela 3). Dos 199 alelos polimórficos, apenas um alelo foi específico da região de Tapes. Contudo, em Santa Vitória do Palmar e Rio Grande, foram identificados seis alelos exclusivos para cada região. Entretanto, estes alelos não estavam presentes em todas as populações de uma mesma região e tampouco em todos os indivíduos de uma mesma população, justificando a ausência de diferenciação regional das populações, assim como a diferença significativa entre populações de uma mesma região.

O padrão de variabilidade genética encontrado indica que a maior parte da variação molecular $(83,68 \%)$ ocorre dentro das populações. No entanto, uma quantidade significativa $(13,67 \%)$ também foi atribuída a diferenças entre as populações dentro de regiões. A variabilidade encontrada dentro das populações avaliadas neste trabalho $(83,68 \%)$ está 
de acordo com a afirmação de Loveless e Hamrick (1984), de que maior variabilidade dentro das populações do que entre elas é típico de espécies que apresentam mecanismos eficientes de dispersão de pólen e de sementes. As afirmações de Miranda et al. (2001) e Galetti et al. (2003), de que os frutos das palmeiras são muito apreciados por mamíferos, aves e répteis, sugerem que este pode ser o caso da espécie deste estudo. No entanto, para corroborar esta hipótese, são necessários estudos que determinem a biologia reprodutiva e o sistema de dispersão desta espécie.

Em outros dois estudos com marcadores AFLP, um com 11 populações de Euterpe edulis (Arecaeae) e outras sete populações de Moringa oleifera (Moringaceae), a porcentagem atribuída à variação dentro de populações foi de cerca de $50 \%$, o que, segundo os autores, é um valor abaixo do comumente encontrado para espécies arbóreas, distribuídas amplamente, com preferência para alogamia e perenes (Cardoso et al., 2000; Muluvi et al., 1999). Entretanto, uma análise de três populações de Eugenia uniflora (Myrtaceae) encontrou $88 \%$ da variação total residindo na diversidade entre populações (Margis et al., 2002).

As oito populações também foram comparadas para verificar a distância entre elas. Das 28 comparações entre as oito populações, foram significativas as diferenças entre 15 populações, com média de $14,72 \%$ da variação molecular atribuída às diferenças entre populações (Tabela 4).

A comparação das populações de duas a duas mostra que entre as populações da região da Ilha dos Marinheiros (município de Rio Grande), exceto entre IM1 e IM3, são encontradas diferenças significativas, com amplitude de divergência de $10,98 \%$ a $15,43 \%$ (Tabela 4 ). Os resultados encontrados na região da Ilha dos Marinheiros sugerem que as populações desta região vieram de diferentes locais, possivelmente introduzidas pelo homem. A análise dos indivíduos destas populações corrobora esta hipótese. No dendrograma (Figura 3), que apresentou coeficiente de correlação cofenética de 0,83 com a matriz de similaridade entre os 46 indivíduos, é nítida uma tendência de agrupamentos formados exclusivamente por indivíduos de cada população desta região. Esta tendência de indivíduos de uma mesma população não ficarem agrupados com os demais indivíduos da região, mostra a presença de variabilidade entre as populações. Segundo Linhart et al. (1981), a diferenciação genética dentro de uma população ou mesmo entre populações de uma espécie pode ocorrer a distâncias relativamente pequenas, e a ocorrência desta diferenciação significa que a variabilidade genética é estruturada no espaço.

O dendrograma (Figura 3) mostra que indivíduos das populações de Santa Vitória do Palmar e Tapes estão dispersos ao longo do dendrograma com a tendência de agrupamento dos indivíduos da mesma região. A comparação das populações de duas a duas pela AMOVA explica esta distribuição, uma vez que não há subdivisão das populações dentro da respectiva região, o que significa que as populações não são estruturadas (Tabela 4).

As populações de Tapes e Arambaré, locais considerados neste estudo como estando em uma única região, não apresentaram diferença significativa quando comparadas pela AMOVA. Este fato pode estar relacionado com a proximidade entre os dois municípios, e ao fato de que as populações sejam oriundas de um mesmo pool gênico original. Também deve ser levado em conta o fato de que possa haver fluxo gênico entre as populações, já que elas estão bastante próximas. Neste caso, a distribuição da variação genética dentro das populações pode ser decorrente da interação de fatores como migração e seleção (Boyle et al., 1990).

Com os dados de presença e ausência de bandas, foi feita uma matriz de similaridade que permite analisar a distância entre os indivíduos. A média geral de similaridade entre os 46 indivíduos foi de $59 \%$, com amplitude de $47 \%$ a $81 \%$. Como indicado por essa matriz (dados não apresentados), as maiores similaridades estão entre dois indivíduos da mesma região, das populações Tapes e Arambaré (81\%), e entre dois indivíduos da mesma população, Celina (80\%). Entretanto, entre dois indivíduos de regiões distintas, Tapes e Santa Vitória do Palmar, também foi encontrada similaridade de $81 \%$, colaborando com a hipótese de que esta espécie apresenta mecanismos eficientes para a dispersão de pólen e sementes.

No gênero Butia, resultados obtidos por Rossato (2007) corroboram esta teoria. Este autor, em um estudo de diversidade entre várias espécies de Butia, encontrou $81 \%$ de similaridade entre dois indivíduos de B. eriospatha de regiões geográficas distintas, um de Erechim e outro de Passo Fundo-RS. A caracterização das cinco espécies de Butia com marcadores ISSR por Rossato (2007) mostrou alta variabilidade e eficiência para separar B. eriospatha das demais espécies. Da mesma forma, Nunes (2007), utilizando RAPD, encontrou alta variabilidade em B. capitata. Porém, nenhum desses estudos considerou a análise molecular da variância para determinar a variabilidade entre e dentro de populações.

Diversos fatores influenciam no nível de diversidade genética nas plantas arbóreas, como sua biologia reprodutiva que, por sua vez, determina 
os padrões de cruzamento e dispersão de genes (Hamrick et al., 1992). Estas espécies, comparadas com outras, apresentam alta variabilidade intraespecífica e, geralmente, mostram menor variação entre populações, particularmente em espécies amplamente distribuídas, alógamas e com sementes dispersadas por animais (Hamrick et al., 1992).

Além disso, a distribuição geográfica e a história evolutiva desempenham importante papel na distribuição da variação genética entre e dentro das populações (Hamrick et al., 1992). Para Allard (1971), a distribuição geográfica é o fator que mais influencia na variação entre plantas. Essa variação pode ocorrer pela presença ou ausência de certos alelos em regiões geográficas específicas (Querol, 1993). No entanto, Cavalli e Winge (2003) consideram o fluxo gênico e o sistema reprodutivo como os fatores mais importantes para a estrutura genética de populações de plantas. É provável que estes fatores tenham tido maior influência na distribuição da diversidade intrapopulacional.

Os índices encontrados neste trabalho podem sugerir que as populações têm uma origem comum, e que foram sofrendo processos de seleção, deriva, isolamento geográfico e mutações que ocasionaram as diferenças entre elas, estruturando-as em subpopulações.

Estudos genéticos com maior amplitude de regiões, populações e indivíduos amostrados podem ser realizados para melhor compreender fatores históricos, físicos e biológicos que modelaram a variação intraespecífica, tais como migração, rotas de colonização, identificação da deriva genética, fluxo gênico e dinâmica das populações (Rivera-Ocasio et al., 2002).

TABELA 1 - Municípios do Rio Grande do Sul onde foram coletadas amostras de Butia capitata utilizadas para análise de divergência genética através de marcadores AFLP.

\begin{tabular}{|c|c|c|c|c|}
\hline Região & Populações (identificação) & $\begin{array}{l}\text { Coordenadas } \\
\text { geográficas }\end{array}$ & $\begin{array}{l}\text { Número de } \\
\text { indivíduos } \\
\text { amostrados }\end{array}$ & $\begin{array}{c}\text { Número de } \\
\text { indivíduos } \\
\text { avaliados }\end{array}$ \\
\hline \multirow{3}{*}{$\begin{array}{l}\text { Santa Vitória } \\
\text { do Palmar }\end{array}$} & Celina $(\mathrm{C})$ & $\begin{array}{l}\text { W } 53^{\circ} 19^{\prime}, 58,3^{\prime \prime} \\
\text { S } 33^{\circ} 28^{\prime} 40,1^{\prime \prime}\end{array}$ & 6 & 6 \\
\hline & Aguiar (A) & $\begin{array}{l}\text { W } 53^{\circ} 18^{\prime} 37,5^{\prime \prime} \\
\text { S } 33^{\circ} 28^{\prime} 39,0^{\prime \prime}\end{array}$ & 6 & 3 \\
\hline & São José (SJ) & $\begin{array}{l}\text { W } 53^{\circ} 18^{\prime} 10,7^{\prime \prime} \\
\text { S } 33^{\circ} 29^{\prime} 08,5^{\prime \prime}\end{array}$ & 6 & 5 \\
\hline \multirow{3}{*}{ Rio Grande } & Ilha dos Marinheiros 1 (IM1) & $\begin{array}{l}\text { W } 52^{\circ} 10^{\prime} 26,8^{\prime \prime} \\
\text { S } 32^{\circ} 01^{\prime} 26,3^{\prime \prime}\end{array}$ & 6 & 5 \\
\hline & Ilha dos Marinheiros 2 (IM2) & $\begin{array}{l}\text { W } 52^{\circ} 08^{\prime} 53,1^{\prime \prime} \\
\text { S } 31^{\circ} 59^{\prime} 03,6^{\prime \prime}\end{array}$ & 6 & 6 \\
\hline & Ilha dos Marinheiros 3 (IM3) & $\begin{array}{l}\text { W } 52^{\circ} 11^{\prime} 5,5^{\prime \prime} \\
\text { S } 31^{\circ} 59^{\prime} 51,0^{\prime \prime}\end{array}$ & 6 & 6 \\
\hline \multirow{2}{*}{ Tapes } & Tapes $(\mathrm{T})$ & $\begin{array}{l}\text { W 512ㅇ'12,2”' } \\
\text { S } 30^{\circ} 52^{\prime} 51,2^{\prime \prime}\end{array}$ & 7 & 6 \\
\hline & Arambaré (Ar) & 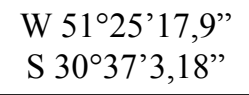 & 12 & 9 \\
\hline TOTAL & & & 55 & 46 \\
\hline
\end{tabular}


TABELA 2 - Número e porcentagem de locos polimórficos e monomórficos por combinação de primers na análise molecular de oito populações de Butia capitata de três regiões do Rio Grande do Sul.

\begin{tabular}{lccccc}
\hline \multirow{2}{*}{$\begin{array}{c}\text { Combinação de } \\
\text { primers EcoRI/ MseI }\end{array}$} & Total de locos & \multicolumn{2}{c}{ Locos polimórficos } & \multicolumn{2}{c}{ Locos monomórficos } \\
\cline { 3 - 6 } & & $\mathrm{n}^{\circ}$ & $\%$ & $\mathrm{n}^{\circ}$ & $\%$ \\
\hline E-AGC/ M-CTT & 42 & 41 & 97,6 & 1 & 2,4 \\
E-AGG/ M-CAG & 63 & 60 & 95,2 & 3 & 4,8 \\
E-ACA/ M-CAG & 48 & 46 & 95,8 & 2 & 4,2 \\
E-ACA/ M-CAT & 61 & 52 & 85,2 & 9 & 14,8 \\
\hline MÉDIA & 53,5 & 50 & 93,5 & 3,75 & 6,5 \\
\hline
\end{tabular}

TABELA3 - Distribuição da variabilidade genética entre regiões, entre populações dentro de regiões e dentro das populações de Butia capitata com base na análise molecular da variância (AMOVA).

\begin{tabular}{lcccc}
\hline Fonte de variação & GL & SQ & $\begin{array}{c}\text { Componentes } \\
\text { da variância }\end{array}$ & $\begin{array}{c}\text { Percentagem da } \\
\text { variação total }\end{array}$ \\
\hline $\begin{array}{l}\text { Entre regiões } \\
\begin{array}{l}\text { Entre populações } \\
\text { dentro de regiões }\end{array}\end{array}$ & 5 & 119,85 & 0,77 & 2,65 ns \\
$\begin{array}{l}\text { Dentro das } \\
\text { populações }\end{array}$ & 38 & 924,84 & 24,34 & $83,68 *$ \\
\hline TOTAL & 45 & 1235,65 & 29,09 & 100,0 \\
\hline
\end{tabular}

*Valores significativos ao nível de $1 \%$ de probabilidade; ${ }^{\text {ns }}$ valores não significativos

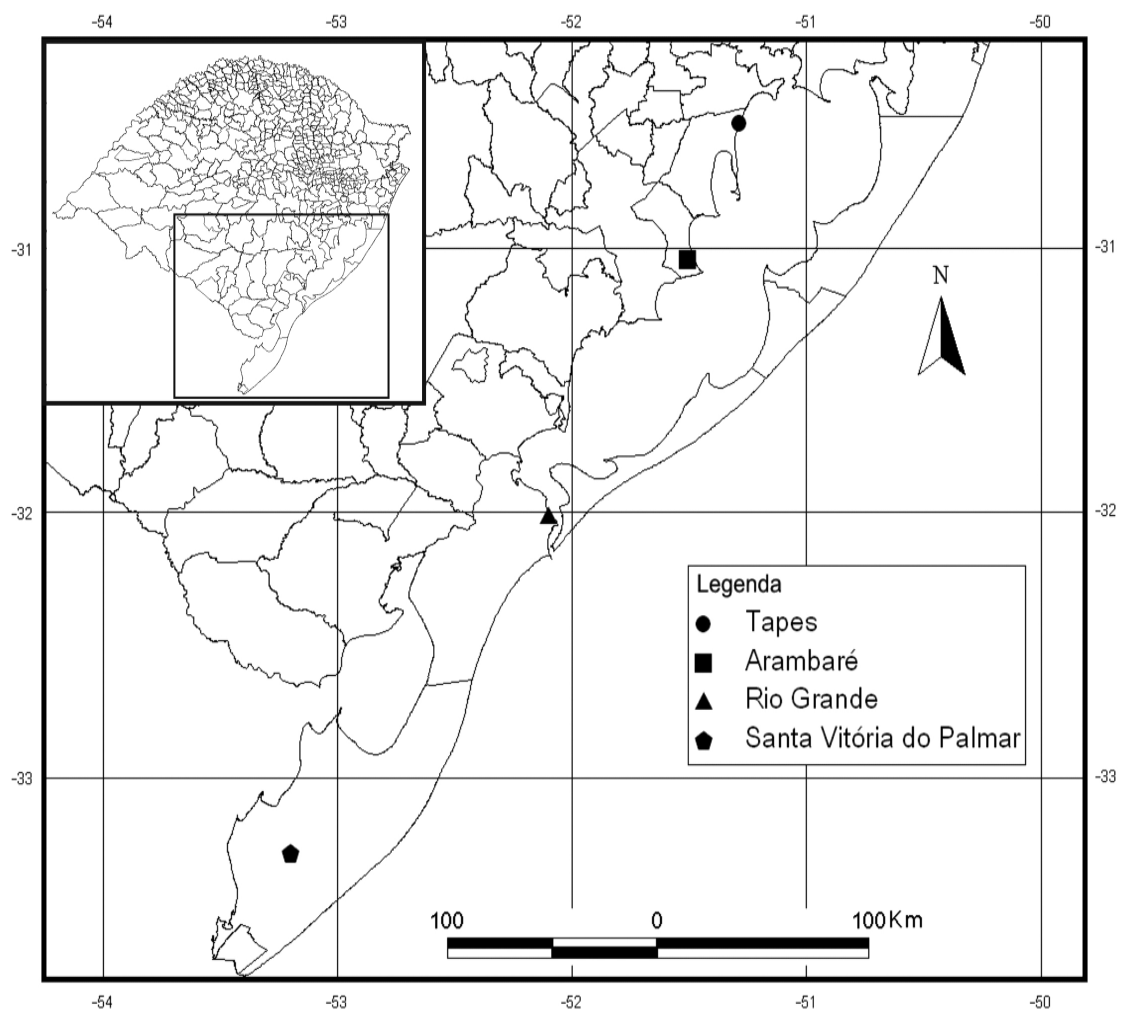

FIGURA 1 - Locais de coleta no Rio Grande do Sul das amostras de Butia capitata utilizadas na análise de variabilidade genética através de marcadores AFLP. 
TABELA 4 - Análise comparativa 2x2 entre populações de Butia capitata obtidas através da AMOVA. A porcentagem da variação molecular total existente entre as populações (Fst) é a medida da distância genética entre as populações. Pelotas, 2008.

\begin{tabular}{|c|c|c|c|c|c|c|c|c|}
\hline Região & \multicolumn{3}{|c|}{ Santa Vitória do Palmar } & \multirow{2}{*}{$\begin{array}{c}\text { Tapes } \\
\mathrm{T} \\
\end{array}$} & \multirow{2}{*}{$\begin{array}{c}\text { Arambaré } \\
\mathrm{Ar}\end{array}$} & \multicolumn{3}{|c|}{ Rio Grande } \\
\hline População & $\mathrm{C}$ & $\mathrm{A}$ & SJ & & & IM1 & IM2 & IM3 \\
\hline $\mathrm{C}$ & - & $2,33^{\mathrm{ns}}$ & $4,50 \mathrm{~ns}$ & $14,99 *$ & $18,44 *$ & $22,09 * *$ & $20,54 * *$ & $12,47 * *$ \\
\hline A & & - & $-1,66^{\mathrm{ns}}$ & $14,84^{\mathrm{ns}}$ & $19,01 *$ & $21,22 \mathrm{~ns}$ & $14,92 \mathrm{~ns}$ & 8,08 ns \\
\hline $\mathrm{SJ}$ & & & - & $8,011^{\mathrm{ns}}$ & $9,56^{\mathrm{ns}}$ & $14,33^{\mathrm{ns}}$ & $8,74 *$ & $10,55 *$ \\
\hline $\mathrm{T}$ & & & & - & $7,43^{\text {ns }}$ & $14,99 *$ & $14,29 *$ & $13,97 * *$ \\
\hline $\mathrm{Ar}$ & & & & & - & $13,26 *$ & $11,06 *$ & $10,73^{\mathrm{ns}}$ \\
\hline IM 1 & & & & & & - & $15,43 *$ & $15,27^{\mathrm{ns}}$ \\
\hline IM 2 & & & & & & & - & $10,98 *$ \\
\hline IM 3 & & & & & & & & - \\
\hline
\end{tabular}

"C" - Celina; “A" - Aguiar, "SJ" - São José; "T” - Tapes; "Ar" - Arambaré; "IM 1" - Ilha dos Marinheiros 1; "IM 2" - Ilha dos Marinheiros 2; "IM 3" - Ilha dos Marinheiros 3.

${ }^{\text {ns }}$ valores não significativos; * valores significativos ao nível de $5 \%$ de probabilidade; ** valores significativos ao nível de $1 \%$ de probabilidade.

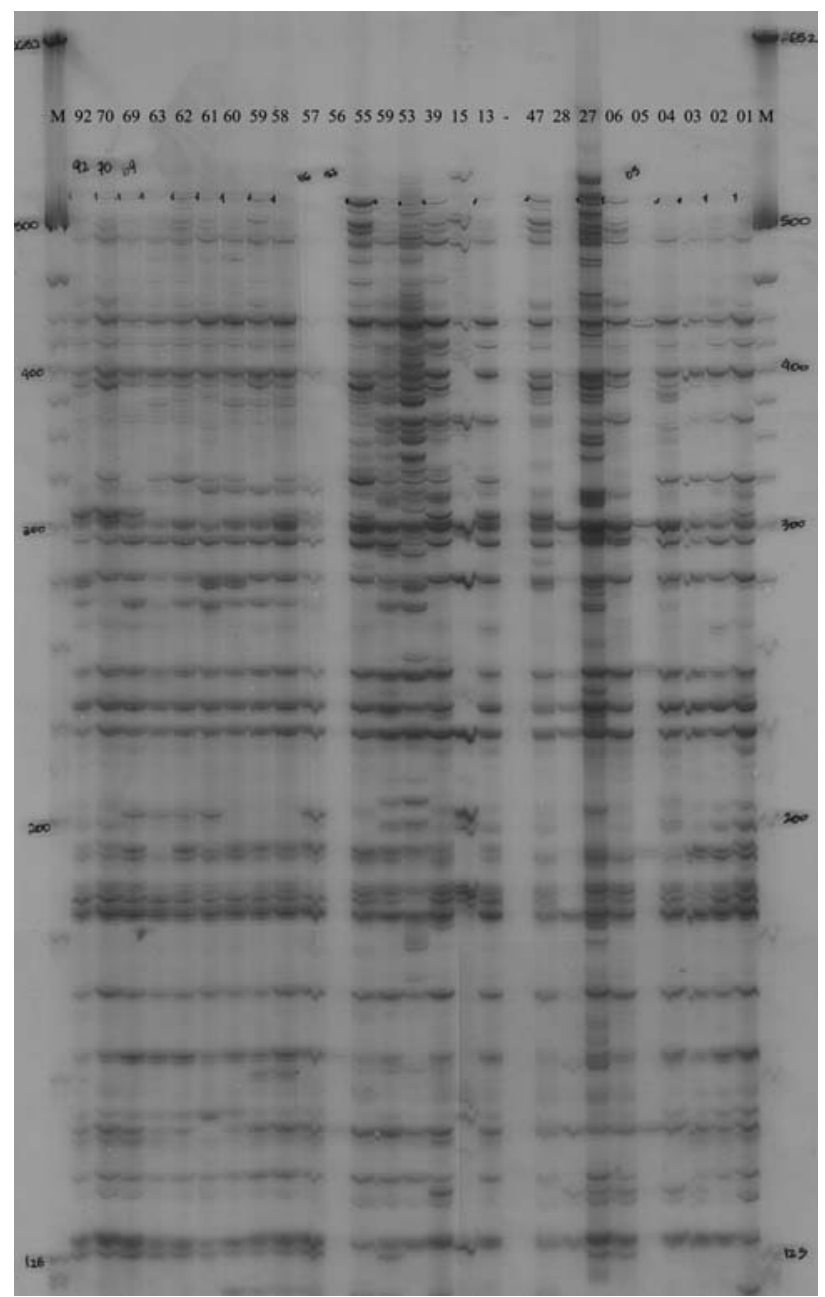

FIGURA 2- Amostras de 27 indivíduos de Butia capitata amplificadas em gel de poliacrilamida 6\% com a combinação de primers E-ACA/ M-CAG. 


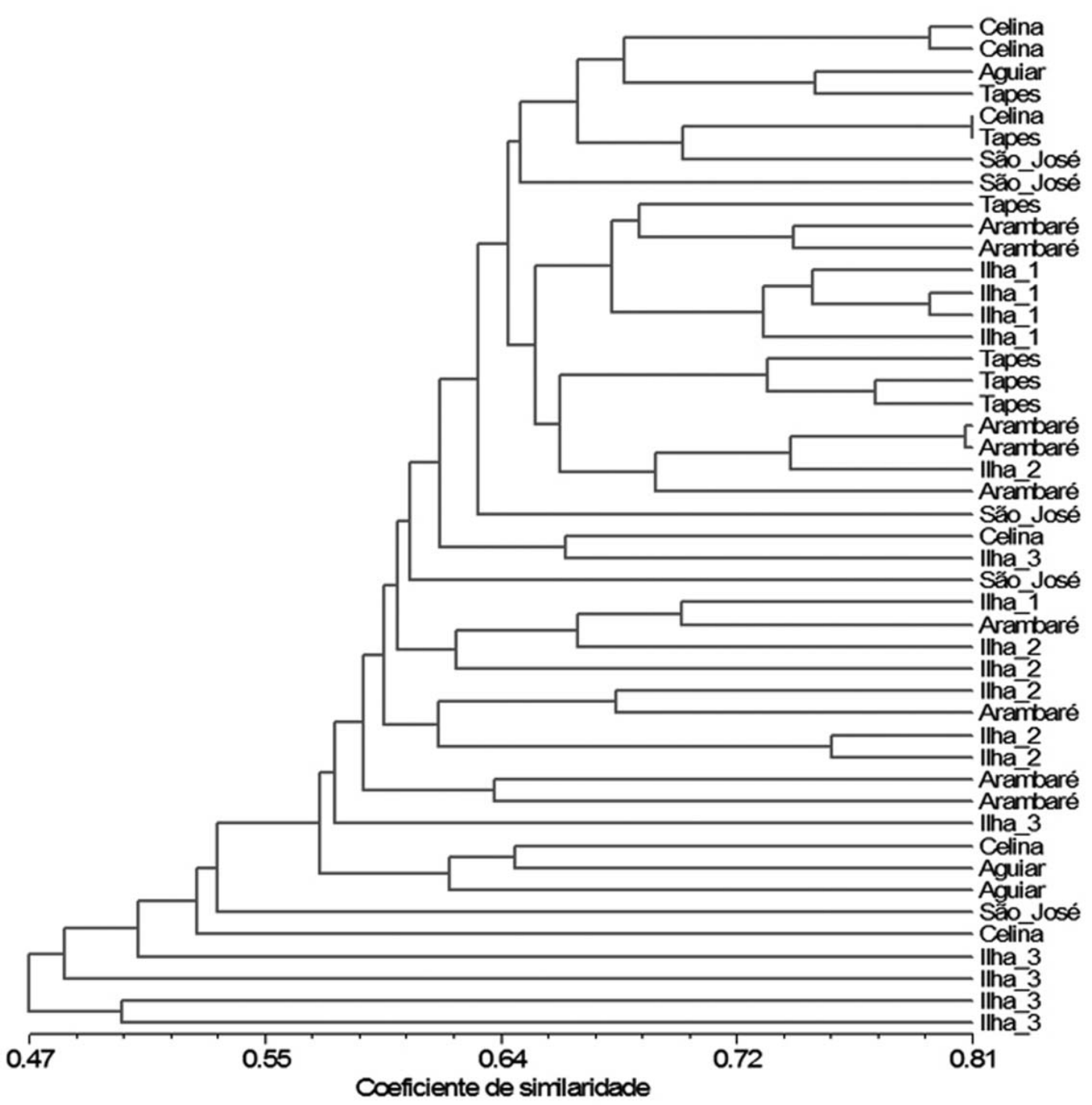

FIGURA 3 - Agrupamento dos 46 indivíduos das oito populações de butiazeiros através da matriz de similaridade calculada pelo coeficiente de Jaccard, utilizando o método UPGMA com base em 199 marcadores AFLP. O coeficiente de correlação cofenético (r) é = 0,83.

\section{CONCLUSÃO}

Os marcadores AFLP foram eficientes para caracterizar a variabilidade genética em populações de Butia capitata. A maior proporção da variabilidade em $B$. capitata encontra-se distribuída dentro das populações. Não foi detectada variabilidade genética entre as regiões, não havendo subdivisão das populações em função do local de ocorrência.

\section{AGRADECIMENTOS}

Os autores agradecem ao CNPq, pela concessão de bolsa de Mestrado e auxílio financeiro através do Edital CT Agronegócio Fruticultura 04/2006, à CAPES e à FAPERGS. 


\section{REFERÊNCIAS}

ALLARD, R.W. Princípios do melhoramento genético das plantas. São Paulo: Edgard Blücher, 1971. $381 \mathrm{p}$.

BONIN, A.; EHRICH, D.; MANEL, S. Statistical analysis of amplified fragment length polymorphism data: a toolbox for molecular ecologists and evolutionists. Molecular Ecology, Oxford, v.16, n.18, p.3737-3758, 2007.

BOYLE, T.; LIENGSIRI, C.; PIEWLUANG, C. Genetic structure of black spruce on two contrasting sites. Heredity, Oxford, v.65, n. 3, p.393-399, 1990.

BRESOLIN-SOARES, A.P. Avaliação de populações de azevém anual quanto à tolerância ao alumínio tóxico e estimativa de tamanho de amostra para estudos de diversidade genética com marcadores AFLP. 2007. 76 f. Dissertação (Mestrado em Agronomia)- Universidade Federal de Pelotas, Pelotas, 2007.

CARDOSO, S. R. S.; ELOY, N. B.; PROVAN, J.; CARDOSO, M. A.; FERREIRA, P. C. G. Genetic differentiation of Euterpe edulis Mart. populations estimated by AFLP analysis. Molecular Ecology, Oxford, v.9, n.11, p.1753- 1760, 2000.

CASTELLANI, R. L.; TARABINI, T.; REIS, A. Biologia reprodutiva de Butia capitata (Martius) Beccari var. odorata (Palmae) na restinga do município de Laguna-SC. Revista Brasileira de Botânica, São Paulo, v. 21, n. 3, p.281-287, 1998.

CAVALLI, S. S. Polimorfismos moleculares. In: FRETAS, L.B.; BERED, F. Genética e evolução vegetal. Porto Alegre: UFRGS, 2003. p.311-332.

CAVALLI, S. S.; WINGE, H. Variabilidade genética em populações naturais. In: FRETAS, L.B.; BERED, F. Genética e evolução vegetal. Porto Alegre: UFRGS, 2003. p.165-176.

CORREA, L. B. BARBIERI R. L., ROSSATO, M. BUTTOW, M.V., HEIDEN, G. Caracterização cariológica de palmeiras do gênero Butia (Arecaceae). Revista Brasileira de Fruticultura, v.31, n.4, pp. 1111-1116, 2009.
CRESTE, S.; TULMANN NETO, A.; FIGUEIRA, A. Detection of single sequence repeat polymorphisms in denaturing polyacrylamide sequencing gels by silver staining. Plant Molecular Biology Reporter, Winnipeg, v.19, n.4, p.299-306, 2001.

DIAS, L.A.S. Análises multidimensionais. In: ALFENAS, A.C. (Ed.). Eletroforese de isoenzimas e proteínas afins: fundamentos e aplicações em plantas e microrganismos. Viçosa: UFV, 1998. p.405-473.

EXCOFFIER, L.; SMOUSE, P. E.; QUATTRO, J. M. Analysis of molecular variance inferred from metric distances among DNA haplotypes: Application to human mitochondrial DNA restriction data. Genetics, Pittsburgh, v.131, n.2, p.479-491, 1992.

FERREIRA, M. E.; GRATTAPAGLIA, D. Introdução ao uso de marcadores RAPD e RFLP em análise genética. Brasília: EMBRAPA-CENARGEN, 1995. 220p.

GAIERO, P.; MAZZELLA, C. Las palmas (Arecaceae) en Uruguay: Análisis cromosómico en especies nativas de Butia, Syagrus y Trithrinax. In: SIMPÓSIO DE RECURSOS GENETICOS PARA AMÉRICA LATINA Y EL CARIBE, 5., 2005, Montevideo. Resúmenes... Montevideo: SIRGEALC, 2005. p.57.

GAlETTI, M.; PIZO, M. A.; MORELlATO, P. Fenologia, frugivoria e dispersão de sementes: métodos de estudos em biologia da conservação e manejo da vida silvestre. Curitiba: Editora UFPR, 2003. p.395-422.

HAMRICK, J.L.; GODT, M.J.W.; SHERMANBROYLES, S.L. Factors influencing levels of genetic diversity in woody plant species. New Forests, Dordrecht, v.6, n.1-4. p.95-124, 1992.

HUFF, D.R.; PEAKALL, R.; SMOUSE, P.E. RAPD variation within and among a natural populations of outcrossing buffalo grass [Buchloë dactyloides (Nutt.) Engelm.]. Theoretical and Applied Genetics, Berlin, v.86, n.8, p.927-934, 1993.

LINHART, Y.B.; MITTON, J.B.; STURGEON, K.B.; DAVIS, M.L. Genetic variation in space and time in a population of ponderosa pine. Heredity, Oxford, v.46, p.407-426, 1981. 
LOVELESS, M.D.; HAMRICK, J. L. Ecological determinants of genetic structure in plant populations. Annual Review of Ecology and Systematics, Palo Alto, v.15, p.65-95, 1984.

MARCATO, A. C. Revisão taxonômica do gênero Butia (Becc.) Becc. (Palmae) e filogenia da subtribo Buttiinae Saakov (Palmae). 2004. 147f. Tese (Doutorado em Ciências) - Universidade de São Paulo, São Paulo, 2004.

MARGIS, R.; FELIZ, D.; CALDAS, J. F.; SALGUEIRO, F.; DE ARAUJO, D. S. D.; BREYNE, P.; VAN MONTAGU, M.; DE OLIVEIRA, D.; MARGIS-PINHEIRO, M. Genetic differentiation among three neighboring Brazil-cherry (Eugenia uniflora L.) populations within the Brazilian Atlantic Rain Forest. Molecular Ecology, Wageningen, v.1, n.11, p. 149-163, 2002.

MIRANDA, I. P. A.; RABELO, A.; BUENO, C. R.; BARBOSA, E. M.; RIBEIRO, M. N. S. Frutos de palmeiras da Amazônia. Manaus: Ministério de Ciência e Tecnologia, Instituto Nacional de pesquisa da Amazônia, 2001. 120p.

MULUVI, G. M.; SPRENT, J. I.; SORANZO, N. Amplified fragment lenght polymorphism (AFLP) analysis of genetic variation in Moringa oleifera Lam. Molecular Ecology, Oxford, v.8, n.3, p. 463 470, 1999.

NUNES, A. M. Caracterização molecular de butiazeiro com o uso de marcadores moleculares. 2007. 59 f. Dissertação (Mestrado em Agronomia) Universidade Federal de Pelotas, Pelotas, 2007.

QUEROL, D. Recursos genéticos, nosso tesouro esquecido: abordagem técnica e socioeconômica. Rio de Janeiro: AS-PTA-Assessoria e Serviços a Projetos em Agricultura Alternativa, 1993. 206p.
RIVAS, M.; BARILANI, A. Diversidad, potencial productivo y reproductivo de los palmares de Butia capitata (Mart.) Becc. de Uruguay. Agrociencia, México, v.8, n.1, p.11-21, 2004.

RIVEIRA-OCASIO, E.; AIDE, T. M.; McMILLAN, O. Patterns of genetic diversity and biogeographical history of the tropical wetland tree Pterocarpus officinalis (Jacq.), in the Caribbean basin. Molecular Ecology, Oxford, v.11, n. 4, p.675-653, 2002.

ROHLF, J. NTSYS-pc: numerical taxonomy and multivariate analysis system. Version 2.1. New York: Exeter, 2001. Software.

ROSSATO, M. Recursos genéticos de palmeiras nativas do gênero Butia do Rio Grande do Sul. 2007. 136 f. Tese (Doutorado em Agronomia)- Universidade Federal de Pelotas, Pelotas, 2007.

ROSSATO, M.; BARBIERI, R. L.; SCHÄFER, A.; ZACARIA, J. Caracterização molecular de populações de palmeiras do gênero Butia do Rio Grande do Sul através de marcadores ISSR. Magistra, Cruz das Almas, v. 19, n. 4, p. 311-318, 2007.

SPOONER, D.; TREUREN, R. van; VICENTE, M. $\mathrm{C}$. de. Molecular markers for genebank management. Rome: International Plant Genetic Resources Institute, 2005. 126 p. (Technical Bulletin, 10)

VOS, P.; HOGERS, R.; BLEEKER, M.; REIJANS, M.; LEE, T.; VANDE; HORNES, M.; FRIJTERS, A.; POT, J.; PELEMAN, J.; KULPER, M.; ZABEAU, M. AFLP: a new technique for DNA fingerprinting. Nucleic Acid Research, Oxford, v.23, n.21, p. 44044414, 1995.

VUYLSTEKE, M.; PELEMAN, J. D.; EIJK, M. JT. V.AFLP technology for DNA fingerprinting. Nature Protocols, v.2, n.6, 2007. 